\section{EL NUEVO DEPOSITARIO Y NUEVA DEPOSITARIA DE JOSÉ JOAQUÍN DE LARRIVA CONTRA GASPAR RICO, MÁS LITERATURA QUE PERIODISMO}

\author{
CONCEPCIÓN REVERTE BERNAL \\ Universidad de Cádiz
}

En el periodismo peruano de los años de la Emancipación sobresalen dos figuras antagónicas, cuyas biografías revelan las contradicciones de los hombres de la época: el limeño José Joaquín de Larriva y Ruiz (Lima, 1780-1832) y el español afincado en el Perú Gaspar Rico y Angulo (La Rioja, ¿-Lima, 1825). Larriva es recordado como un autor satírico notable, en la estela de la serie de poetas que va de Mateo Rosas de Oquendo en adelante, y como precursor del costumbrismo romántico. Antes de entrar en sus diatribas contra Gaspar Rico, conviene recordar algunos datos biográficos suyos ${ }^{1}$ : Larriva procedía de una familia respetada, pues era hijo del naviero limeño don Vicente de Larriva, según Manuel de Mendiburu, «persona distinguida por su comportamiento digno y benéfico» ${ }^{2}$. Formado en el Convictorio de San Carlos en tiempos del sacerdote Toribio Rodríguez de Mendoza, representante de la Ilustración cristiana en el Perú ${ }^{3}$, obtuvo el grado en Artes, Teología, Derecho Civil y Canónico, siendo ordenado sacerdote. En relación a su ministerio sagrado parece que su vocación no debió de ser tan profunda, pues llegó a escandalizar con comportamientos inadecuados, faltando en él lo primordial, la caridad, como se indica ${ }^{4}$. Fue Profesor de la Universidad de San Marcos, la otra institución que forjó a los ideólogos de la Emancipación, y su inteligencia y preparación le valieron el encargo de rendir honores a diversos personajes del período, a lo cual siempre accedió acomodándose a los vaivenes políticos. Así, es autor de una Oración fúnebre por María Antonia de Borbón, Princesa de Asturias (1807); de un Elogio al Virrey don José Fernando de Abascal, quien lo nombró Capellán del regimiento de la Concordia y Coronel de dicho cuerpo, llamado de este modo por el título nobiliario del Virrey (1813); hace el Elogio del Arzobispo del Perú, el Excmo. Sr. D. Bartolomé María de las Heras (1815); un Panegírico de la Concepción de María (1816); el Sermón en la solemne Misa de acción de gracias en el recibimiento del Virrey Pezuela por la Universidad (1816); la Oración fúnebre en las solemnes exequias de los oficiales españoles asesinados en la Punta de San Luis (1819); pero también, la Oración fúnebre en la Catedral de Huamanga, por los patriotas fallecidos en la batalla de Junín (1824); una Necrología del Doctor José Faustino Sánchez Carrión, quien fuera amigo suyo (1825); un Elogio de D. Si-

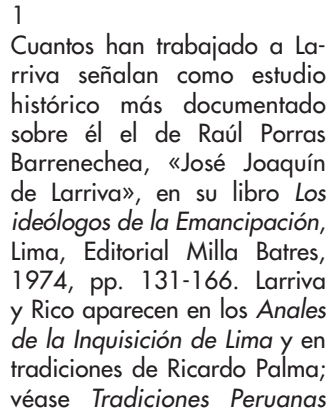

Completas, Edith Palma (ed. y pról.), Madrid, Aguilar, 1961. Huelgan comentarios sobre la peculiar historicidad de las obras de Palma, donde resulta difícil deslindar hoy lo real de lo inventado.

2

Véase la entrada que le dedica en su Diccionario históricobiográfico del Perú, Segunda edición con adiciones y notas bibliográficas publicada por
Concepción Reverte Bernal: Catedrática de Literatura Hispanoamericana por la Universidad de Cádiz, ha publicado los siguientes libros: Aproximación crítica a un dramaturgo virreinal peruano: $F$ r. Francisco del Castillo («el Ciego de la Merced») (1985); El teatro de Fr. Francisco del Castillo («el Ciego de la Merced») (1988); Articulación temática en la narrativa y teatro de Mario Vargas Llosa. Visión del Perú (1994); con César Oliva (eds.): I Congreso Iberoamericano de Teatro. Pedagogía Teatral: Conceptos y Métodos (1996); Fuentes europeas - Vanguardia hispanoamericana (1998), con Mercedes de los Reyes (eds.): II Congreso Iberoamericano de Teatro: América y el Teatro Español del Siglo de Oro (1998); Teatro y Vanguardia en Hispanoamérica, (2006). Es además autora de bastantes artículos y comunicaciones en Congresos sobre Literatura Hispanoamericana.

Evaristo San Cristóval, Lima, Imprenta «Enrique Palacios», 1931. Véanse además las entradas que hace Mendiburu a Larriva y a Rico y de Manuel Zanutelli Rosas a ambos, en la Enciclopedia biográfica e histórica del Perú. Siglos XIX-XX Carlos Milla Batres (ed.), Lima, Editorial Milla Batres, 1994.

Cf., por ej., el clásico de Felipe Barreda Laos, Vida intelectual del Virreinato del Perú, Lima, UNMSM, 1964 ( $3^{\circ}$ ed.) o José A. de la Puente Candamo, La Independencia del Perú, Madrid, Editorial MAPFRE, 1992.

4

En la apreciación coinciden, por ej., Porras Barrenechea, op. cit. Ventura García Calderón, (ed.), Costumbristas y satíricos, París, Desclée de Brouwer, 1938, vol. I, pp. 68-98; Luis Alberto Sánchez, La Literatura Peruana. Derrotero para una Historia Cultural del Perú, Lima, Editorial Mejía Baca, 1981, t. III, pp. 829-835. Larriva no gusta a José de la Riva-Agüero, aunque reconoce su ingenio, en Carácter de la Literatura del Perú Independiente, Obras Completas, Lima, Pontificia Universidad Católica del Perú, 1962, t. I, pp. 93-95.

El Nuevo Depositario y Nueva Depositaria de José Joaquín de Larriva contra Gaspar Rico, más literatura que periodismo

CONCEPCIÓN REVERTE BERNAL 
5

Cito por Colección de documentos literarios del Perú, colectados y arreglados por el Coronel de Caballería de Ejército, fundador de la Independencia, Manuel de Odriozola, Tomo II, Lima, Establecimiento de tipografía y encuadernación de Aurelio Alfaro, 1864, donde se halla reunida la mayor parte de sus obras. Porras Barrenechea, op. cit., explica que algunos de estos poemas se han considerado también del impresor Bernardino Ruiz, con el que trabajó Larriva, pero él se inclina por la autoría de Larriva. Para la poesía del período véase además Luis Monguió, "La poesía y la Independencia, Perú 1808-1825», en Literatura de la Emancipación Hispanoamericana y otros Ensayos, Memoria del XV Congreso del IILI, Lima UNMSM，1972, pp. 7-15; Aurelio Miró Quesada Sosa (ed.), La poesía de la Emancipación Lima, Comisión Nacional del Sesquicentenario de la Independencia del Perú, 1971.

6

Este teatro ha merecido ser reproducido posteriormente, por ej., en Guillermo Ugarte Chamorro, El teatro en la Independencia, Lima, Comisión Nacional del Sesquicentenario de la Independencia del Perú, 1974, vol. I, pp. 285-306; Carlos Miguel Suárez Radillo, El Teatro Neoclásico y Costumbrista Hispanoamericano. Una historia crítico-antológica, Madrid, Ediciones Cultura Hispánica. Instituto de Cooperación Iberoamericana, 1984, vol. I, pp. 330-341. No se incluye a Larriva, en cambio, en Ricardo Silva-Santisteban (ed.), Antología General del Teatro Peruano, t. IV: Teatro Republicano. Siglo XIX, Lima, Banco Continental. Pontificia Universidad Católica del Perú, 2001.

7

Cf. Ascensión Martínez Riaza La prensa doctrinal en la Independencia del Perú 1811-1824, Madrid, Cultura Hispánica. Instituto de Cooperación Iberoamericana, 1985; Daniel Morán María Aguirre y Frank Huamaní, Lima a través de la Prensa, Lima, Colección Historia de la Prensa Peruana: 2, 2008; Alberto Varillas Montenegro, El periodismo en la historia del Perú. Desde sus orígenes hasta 1850, Lima, Universidad de San Martín de

El Nuevo Depositario y Nueva Depositaria de José Joaquín de Larriva contra Gaspar Rico, más literatura que periodismo

CONCEPCIÓN REVERTE BERNAL

món Bolívar en la Universidad de San Marcos (1825). Paralelamente, como escritor satírico, se le atribuye un poema dedicado a escarnecer la Inquisición, después de haber suscrito un documento contra la misma, una vez declarada su abolición en 1813, y otros poemas donde anticipa la retirada de las tropas españolas del Perú («Las profecías del Cojo Prieto») o manifiesta su rechazo a las huestes bolivarianas que permanecen en el país («El fusilico del General Flores», contra el prócer alabado por José Joaquín de Olmedo, y «El Sacre», contra don José Antonio de Sucre). Comienza «El fusilico» con unos versos que contienen una idea que se repite en «El Sacre» y suele recordar la crítica:

\section{Cuando de España las trabas}

en Ayacucho rompimos,

otras cosas más no hicimos

que cambiar mocos por babas 5 .

De su teatro se conserva el sainete La ridiculez andando o la medalla de López (1813) y se le atribuye El café (1814), siendo autor de ágiles diálogos ${ }^{6}$. En su faceta de intelectual que llena con sus escritos las páginas de los periódicos, de diverso signo, a fines del XVIII e inicios del siglo XIX, Larriva firmará con su nombre o bajo seudónimos (como el citado "Cojo Prieto", por un defecto físico real) en la Gaceta del Gobierno de Lima, El Cometa, El Verdadero Peruano, El Investigador, El Argos Constitucional, El Nuevo Depositario y Nueva Depositaria, entre otros. Precisamente, en algunos de estos periódicos tendrá como contendiente a don Gaspar Rico y Angulo, quien defenderá su postura de liberal reformista contrario a la Independencia de España, desde El Peruano, El Investigador y El Depositario. Este auge periodístico comenzará con

Porres, 2008; Manuel Zanutelli Rosas, Periodistas Peruanos del Siglo XIX. Itinerario Biográfico, Lima, Universidad de San Martín de Porres, 2006. Lamentablemente no he podido consultar la Historia de la Prensa Peruana 1594-1990, de Juan Gargurevich Regal. Hizo un valioso sumario de los «Periódicos de la época colonial impresos en Lima» Carlos Prince, en su Bosquejo de la Literatura Peruana Colonial. Causas favorables y adversas a su desarrollo, Lima, Biblioteca Peruana de la Colonia II, Impreso en casa del autor, 1910-1911, pp. 229-242.

8

Op. cit., p. 154. La estampa, que es más extensa, empieza con esta frase y continúa en la página siguiente.

9

En la bibliografía que he consultado se mencionan, al menos, un poema en recuerdo de él de José Pérez de Vargas y otro de José Joaquín de el decreto de libertad de prensa promulgado por las Cortes de Cádiz en 1810, que llegará al Perú un poco más adelante; tras el cual vendrá una nueva represión conservadora, que ya no podrá silenciar las voces de los dos bloques en conflicto, el de los realistas y el de los insurgentes 7 . Desde 1828, Larriva sostendrá además una agria disputa con $\mathrm{Fe}$ lipe Pardo y Aliaga por diferencias respecto al teatro, del que Larriva se consideraba una voz autorizada; este enfrentamiento se intensificará con el estreno de Los frutos de la educación de Pardo, el 6 de agosto de 1830, pues, para Larriva, Pardo era un petimetre. El historiador Raúl Porras Barrenechea define, en síntesis, a Larriva como "un espíritu inquieto y desadaptado» ${ }^{8}$. Su carácter difícil y sus sátiras debieron de causarle numerosos enemigos, uno de ellos, al que zahiere con apasionamiento, Gaspar Rico; sin embargo, también supo granjearse amigos, algunos de los cuales lo homenajearon a su muerte con sendos poemas?.

El español Gaspar Rico y Angulo, nacido en Nalda (La Rioja), era hijo legítimo de don Joaquín Rico y doña María Angulo Tricio y Querejazo. Debió de llegar al Perú hacia 1793 y allí gozó de una buena posición económica y social. En 1803 es diputado por Puno en el Tribunal de Minería; más adelante ejerce como administrador de la Casa de los Cinco Gremios Mayores de Madrid en Lima, cargo por el que es acusado de malversación de fondos junto con don Antonio Taranco, lo cual le hace viajar a España para su defensa, saliendo ambos exculpados de ello. Durante su estancia en la península, Rico consigue ser nombrado Ministro honorario de las Cajas Rurales y Director general de la Lotería de América Meridional, juego que empieza a funcionar a su vuelta al Perú. En tiempos del Virrey Abascal, formará parte del Batallón de Comercio como Capitán de Granaderos, pero sus ideas constitucionalistas, expresadas en El Peruano (1811-1812) produjeron su detención y destierro a España en 1812, de donde volvió a Perú con una postura más conservadora. Durante el gobierno del Virrey Pezuela se convirtió en asesor económico del mismo y, una vez depuesto éste, se aproxima al Virrey La Serna, al que acompaña en su marcha por el interior del Perú desde 1821, a raíz de la declaración de la Independencia en Lima. En este recorrido, La Serna lo nombrará Intendente de Huancavelica. Finalmente, 
Rico se refugiará en el Callao con el contingente de las últimas tropas españolas del Perú comandadas por José Ramón Rodil, lugar donde enfermará y fallecerá en 1825, poco antes de la rendición de la plaza, tras una muy valerosa resistencia. Entre 1821 y 1825 Rico escribirá el periódico El Depositario en defensa de las ideas realistas. También él firmará sus artículos con seudónimos: «El invisible», «El invariable», «Moncada», «El anciano», «Renato Jerisile de la Bañeza» ${ }^{10}$. Casi todos los que han manejado los escritos de Rico en el período final de su vida los califican de zafios y carentes de interés; sus graves insultos a los patriotas, incluyen al General San Martín y a Simón Bolívar, lo cual ayuda a entender su descrédito. Larriva y Rico son considerados por Ascensión Martínez Riaza y Alberto Varillas Montenegro ${ }^{11}$, miembros de la segunda generación del periodismo peruano, en el siglo XIX, junto con Fernando López Aldana, Bernardo de Monteagudo, Francisco Javier Mariátegui, José Gregorio Paredes, Manuel Villalta, Felipe Lledías, José María de Pando; la primera generación sería la correspondiente a los autores del célebre Mercurio Peruano. Son también coetáneos de Larriva los poetas José Manuel Valdés, José Joaquín de Olmedo y Mariano Melgar.

José Joaquín de Larriva arremete contra Gaspar Rico en su poema heroico-satírico La Angulada, publicado sin fecha, del que se conocen únicamente la dedicatoria y el canto I, aunque en el título de la impresión se diga que consta de doce cantos, lo cual hace suponer que está concluido cuando aparece esta parte ${ }^{12}$. Aquí vemos emplear a Larriva algunos recursos que están también en $E l$ Nuevo Depositario y la Nueva Depositaria, como ciertos tipos de comicidad verbal o el hecho de acompañar el texto escrito con alguna ilustración satírica alusiva (la portada de $L a$ Angulada presenta a un torero con la espada dirigida al toro frente a él). Por ejemplo, el subtítulo de La Angulada es: "Historia de Don Gaspar Rico, Angulo, Tricio, Querejazu, Reynares, Ruiz de Lovera, Aragón, Gonzales, Torres y Villasana, ministro honorario de la hacienda pública, director general de la Lotería nacional de la América meridional, escritor del Depositario, etc., etc., etc., etc., etc., etc., etc., etc., etc., etc., etc., etc., etc., etc., etc., etc., etc., etc. [sic, 18 veces etc.]»; como veremos en los periódicos, la larga serie de apellidos del español será un motivo de burla reincidente.

El poema va firmado por «A. B. C. D. E. F. G. H. I. J. K. L. M. N. O. P. Q. R. S. T. V. U. X. Y. Z.». En su «Dedicatoria a Tito ${ }^{13}$, Emperador romano y conquistador de Jerusalén", Larriva invoca a éste como auspiciador del poema contra Rico, por ser el Emperador Tito, según el historiador Dion Casio a quien se cita, inventor del juego de lotería. En la hipérbole cómica de Larriva, la invención de la lotería dará mayor fama al Emperador que la conquista de Jerusalén, por ser Angulo su heredero:

Y que si antes te ha dado gloria tanta la gran conquista de la Tierra Santa, ha de darte desde hoy más nombradía la invención de la nueva lotería; pues hablando, Señor, sin disimulo, te honran más esas bolas de madera con que elevaste a superior esfera al inmortal Angulo, honor y gloria de los países godos, que esa espada de acero y esos bríos con que en el sitio que sabemos todos hiciste pedir pita a los judíos.

Nadie dudó jamás que es más portento hacer un héroe que destruir un ciento ${ }^{14}$.

Dedicatoria y canto I están escritos en silva, como las partes de La Gatomaquia de Lope de Vega, a excepción del inicio del canto, donde Larriva intercala la siguiente décima con un pie quebrado («casi décima» o «no décima» dirá en los periódicos), a modo de resumen encomiástico:

Del célebre varón canto las glorias

a quien buscarle par en las historias perder el tiempo es, cansarse en vano; pues de non anda en el linaje humano. De aquel que con el ruido de su nombre que va de zona en zona, tiene atónito al orbe y aturdido, y a quien la fama sin cesar pregona con tal fuerza y tesón que cada día rompe un clarín, trompeta o chirimía.

10

Dedica especial atención a Rico Martínez Riaza, op. cit. No he llegado a leer artículos de Rico, sólo algún fragmento en Morán y otros, op. cit. El uso de los seudónimos es frecuente durante esos años por las circunstancias políticas (cf. de la Puente Candamo, op. cit.). Rico tuvo asimismo amigos influyentes entre los patriotas, de los que se acabó distanciando.

11

Op. cit. Véase además Alberto Varillas Montenegro,

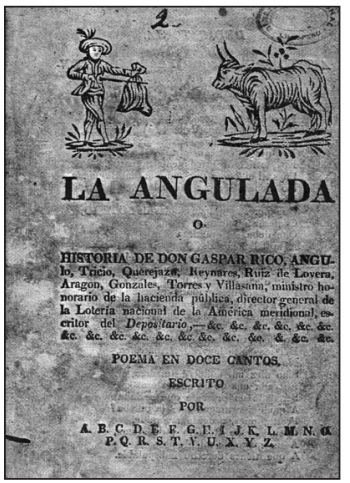

Portada de La Angulada, tomada de Ascensión Martínez Riaza, La prensa doctrinal en la Independencia del Perú 1811 1824, Madrid, Cultura Hispánica, 1985, p. 85.

La Literatura Peruana del Siglo XIX. Periodificación y Caracterización, Lima, Pontificia Universidad Católica del Perú, Fondo Editorial, 1992

12

Martínez Riaza (op. cit., p. 77) dice que la publicación carece de fecha, pero en ibid., p. 85, sin explicar el motivo, data el poema en 1825; véase también José Toribio Medina, La imprenta en Lima (1584-1824), Santiago de Chile, Imprenta y grabado en casa del Autor, MCMIV (Ed. facsímil, Amsterdam, N. Israel, 1965), t. IV, p. 361.

13

Ya que no he podido disponer del impreso antiguo, cito por la edición de obras de Larriva hecha por Odriozola, op. cit. Aunque el Coronel parece, en general, cuidadoso al transcribir los textos, se deslizan ciertas erratas. En su edición, Odriozola transcribe aquí Tito Livio, con la confusión del nombre del historiador con el del Emperador Tito; corrijo este error, que presumo del impresor o editor antes que de Larriva, a quien suelen calificar de buen latinista.

14

Pita = lat. pietas, 'piedad'. Odriozola acaba este verso con la palabra "cuento», que presumo error por «ciento».

El Nuevo Depositario y Nueva Depositaria de José Joaquín de Larriva contra Gaspar Rico, más literatura que periodismo CONCEPCIÓN REVERTE BERNAL 
Resulta un lugar común de la crítica sobre Larriva. Véanse además Augusto Tamayo Vargas, Literatura Peruana, Lima, UNMSM, 1965, t. I, pp. 397-400 Alberto Tauro, Elementos de Literatura Peruana, Lima, Imprenta Colegio Militar Leoncio Prado 1969 (2 ed.), pp. 99-100; Was hington Delgado, Historia de la Literatura Republicana. Nuevo carácter de la literatura en el Perú independiente, Lima, Rikchay Perú, 1984, pp. 53-55; Jorge Cornejo Polar, "Costumbrismo y periodismo en el Perú del siglo $X \mid X »$, en su Estudios de literatura peruana, Lima, Universidad de Lima. Fondo de Desarrollo Editorial - Banco Central de Reserva. Fondo Editorial, 1998 pp. 75-105.

17

He manejado El Nuevo Depositario. Nueva Depositaria [ed. facsímil], Homenaje de la Biblioteca Nacional al Sesquicentenario de la Emancipación del Perú, Lima, Separata de Boletín de la Biblioteca Nacional (57-58), 1971; cito por esta edición, cotejándola con la recopilación de obras de Larriva por Odriozola. Mantengo las grafías onomatopéyicas, subrayados, repeticiones, como en el impreso antiguo. Véase también Medina, op. cit. y La imprenta en Arequipa, el Cuzco, Trujillo y otros pueblos del Perú durante las campañas de la Independencia (1820-1825). Notas bibliográficas, Santiago de Chile, Imprenta Elzeviriana, 1904. Durante esos años destacan como impresores Bernardino Ruiz, Guillermo del Río y Manuel Peña.

El Nuevo Depositario y Nueva Depositaria de José Joaquín de Larriva contra Gaspar Rico, más literatura que periodismo

CONCEPCIÓN REVERTE BERNAL
La parodia del género épico supone la imitación de su estilo, con la referida hipérbole para encarecer el ilustre origen y los méritos del héroe, hipérbatos, adjetivos cuidadosamente seleccionados, acumulación, voces o referencias cultas (que en este caso van unidas a vulgarismos), etc. Entre los pasajes del canto me parece destacable la siguiente enumeración totalizadora, que exalta el ingente número de plumas necesario para escribir el poema de Angulo:

Era también indispensable cosa que tuviese plumas y cañones, de todas las putillas y gorriones, lechuzas, gallinazos, papagayos, alcatraces, cernícalos y gallos ${ }^{15}$; y de cuanto volátil ha existido, en el aire, en la jaula y en el nido, de toda edad y clase, y nombre y pinta, tanto hembras como machos, desde que el Dios que habita el firmamento pobló con ellos la región del viento; inclusos los que encerró en el Arca el célebre Patriarca

a quien tanto veneran los borrachos, porque el árbol plantó del aguardiente; $y$, en fin, que se volviesen de repente, papel los cielos y los mares tinta.

Como mencioné al principio, Larriva es considerado un anticipador del costumbrismo romántico ${ }^{16}$ y si arriba habla de "gallinazos, papagayos, alcatraces», el vate de Angulo pronuncia:

-Ensílenme el Pegaso

que me voy hasta arriba del Parnaso, y pónganme en la alforja un gran porongo,

Me brincan las ideas y me saltan; cosas muy grandes sin cesar me fluyen, y los versos así de ciento en ciento entre mi cráneo bullen, cual bullen los frijoles, cuando hierven las pailas o peroles en la cocina de cualquier convento;

La parodia de la altura heroica contrasta con el descenso a la cotidianeidad criolla, y así, Larriva cierra el canto diciendo con un peruanismo:

Y supuesto que estoy asegurado ya de tu alto auspicio, con el cual hacer puedo tanto verso que deje sonso a todo el universo, sin perder un momento,

voy a empezar tu historia. Va de cuento.

Al leer El Nuevo Depositario y la Nueva Depositaria los historiadores rechazan su condición de fuentes fiables, es decir, su capacidad informativa; sin embargo, para un historiador de la Literatura, esa falta de historicidad no es un demérito, siempre y cuando los textos posean cualidades literarias que los hagan dignos de recibir atención. El objetivo de los cinco números de El Nuevo Depositario y del único número de la Nueva Depositaria ${ }^{17}$, que Larriva da a publicar entre el 18 de agosto de 1821 (vale la pena recordar que la Independencia del Perú se proclama el 28 de julio del mismo año) y el 1 de mayo de 1825, es decir, mientras Rico acompaña a las tropas españolas publicando su Depositario por el interior del Perú hasta terminar en el Callao, no es otro sino denigrar a Gaspar Rico, convirtiéndolo en un personaje ridículo a los ojos de los lectores, y bajo este punto de vista Larriva es muy eficaz. La sátira contra Gaspar Rico posee diferentes vertientes que iré mostrando.

En primer lugar, Larriva se burla de las situaciones reales que atraviesa Rico; lo imagina: a) cargando sus letras de imprenta y bolas de lotería en la huida de los españoles hacia el interior del Perú, b) contento por la Intendencia de Huancavelica, donde es recibido por las autoridades locales, c) resguardándose de las bombas que caen a su alrededor en el sitio del Callao, como si fuesen fuegos de artificio, inocuos para quienes las reciben. Los textos periodísticos empiezan con un «Prospecto en forma de diálogo entre el editor y un amigo suyo", donde Larriva apuesta a su amigo que es capaz de imitar el estilo de los Depositarios de Rico, de ahí el título que pondrá a sus publicaciones:

- ¡Qué! ¿Estoy yo loco? Lo que pienso es escribir un periódico que parezca escrito con la pluma de Rico; no porque contenga insultos y dicterios, sino porque imite en todo su lenguaje.

- Ni los demonios del infierno son capaces de imitar el lenguaje de Rico. Se me figura esa cabeza al caos de los poetas o a la torre de Babilonia cuando se confundieron las lenguas.

Tras este diálogo en prosa, Larriva ofrece una ensalada de textos en prosa y verso que 
giran en torno al tema principal que centra cada periódico.

El primer número de El Nuevo Depositario continúa con un «Variando sin variar la variación», forma de hacer periodismo amplificando la noticia:

Si vale una noticia, se dice y se cree que Don Gaspar Rico y Angulo que, no por miedo, sino por vergüenza, salió de Lima escoltado por las tropas españolas; perdió todo su equipaje en el río de Cañete. Si valen dos noticias, se dice y se cree que, poco antes de Coillo, se cayó del caballo y dio un costalazo más que regular. Si valen tres noticias, se dice y se cree que el caballo no pudo resistir el formidable peso de la alforja en la cual iba la imprenta y los globos de la Lotería, y se cayó muerto al llegar a Pacarán. Si valen cuatro noticias $[\ldots .$.

Tras esto leemos una «No décima ${ }^{18}$ en loa de D. Gaspar Rico y Angulo», que en este caso sí es una décima espinela, aunque no de alabanza sino de repudio; a la que sigue una «No octava ${ }^{19}$ en que se da al burro un consejo saludable», que resulta asimismo una octava real. Pienso que otro aspecto interesante de la capacidad literaria de Larriva es su dominio de la versificación, donde lo mismo maneja con destreza formas métricas habituales, como se permite modificarlas avisando de esto falsa o certeramente al lector. El núcleo de este primer Nuevo Depositario estriba en el supuesto «Diálogo intermediario entre el Borrico y Rico, o entre Rico y el Borrico, que todo viene a ser la mesma cosa», en el que el jumento resulta más sagaz que su amo al protestar por la pesada carga que lleva. Hay que comentar al respecto que la fábula, por su didactismo, es un género propio del Neoclasicismo y que de Larriva se conservan dos: «La Araña» $\mathrm{y}$ «El Mono y los Gatos» ${ }^{20}$. Además, el asno o borrico es un animal que sobresale en fábulas del XVIII, al encarnar la falta de razón. En el texto de este «Diálogo intermediario», Larriva cita dos versos de la fábula «El león envejecido» de Samaniego, cuyo título y asunto pueden aplicarse metafóricamente al fiero articulista Rico, ahora en declive: «Éste es doble morir; no hay sufrimiento,/ porque muero insultado de un jumento» ${ }^{21}$.

Un rasgo continuo en la forma de hablar de Rico es su carácter ridículo por afectado. Rico emplea el plural mayestático y su discurso resulta redundante mediante repeticiones, sinonimia, políptoton, «variaciones» (como antes); burla, en definitiva, de una retórica barroca decadente, escasa de contenidos. Leyendo a Larriva aquí uno evoca el modo de expresarse de Groucho Marx o del mexicano Cantinflas, con un lenguaje deconstruido:

RICO [...] Nos somos aquel escritor melifluo que tanto trabajó en enseñar o instruir a los limeños o no limeños con escritos extensos o profundos. Con los cincuenta Depositarios que escribimos, dimos a Lima una cuarta parte de ilustración. Si ciento más, tres cuartos de ilustración. Y si ciento y cincuenta más, una ilustración íntegra o completa; es decir, no mediana ni pequeña. Y ¿cuál ha sido la recompensa que hemos recibido por tantas y tantas veladuras y por tantos y tantos calentamientos de cabeza? [...] nos han insultado, nos insultan o nos insultarán.

Ante el discurso de Rico encareciendo su carga, el Borrico le responde como un hombre de formación ilustrada, rechazando el juego de lotería como un vicio social que es preciso erradicar:

BORR. Basta, basta y basta Señor Don Gaspar Rico y Angulo [...]; hágame Ud. el gusto de apearse en el momento y de quitarme de encima sus preciosos e importantes trebejos, que yo, desde pollino, he vivido siempre con la mayor conducta y borriquía de bien, y no es razón que deshonre estas canas que peino, cargando al cabo de la vejez instrumentos de maldades [...] Los globos de la Lotería Nacional de la América Meridional no tienen otro objeto que estafar a los pueblos, y los caracteres de esta imprenta sólo son para insultar a los hombres de bien.

Después de apearse del jumento, Rico se resignará entonando una canción, escrita en forma onomatopéyica; una más entre las abundantes onomatopeyas que prestan vivacidad y tono coloquial a estos textos periodísticos ${ }^{22}$ :

RICO [...] y, para divertir el camino, entonemos la cantinela que entonamos cuando fuimos a pata hasta el Callao, por no haber encontrado un demonio en forma de aguilucho que nos llevase por los aires ${ }^{23}$ : Tara rara... No era así. Tara rera... Tampoco. Tara rira... Tampoco. Tara rora... Tampoco. Tara rura... Menos..

Tran larán. Éste es el compás de dos por cuatro que yo buscaba.

Tran, larán, larán, lan; tran larán larún; tran, larán, larán, larán, lan; tran larún, larún.
18

Aquí el subrayado es mío.

19

ld.

20

Odriozola, op. cit. Su coetáneo Mariano Melgar también escribe fábulas.

21

Cf. Félix M. Samaniego, Fábulas, Alfonso I. Sotelo (ed.), Madrid Cátedra, 1997, Libro tercero, fábula IV, pp. 247-248.

22

Por ej., en este mismo Depositario: "Tum, tum, tum. Deo gracias», "comienzo a dar respingos y trum, trum, trum, salvaje en tierra», «izas!».

23

Parece pensar aquí en la novela picaresca El Diablo Cojuelo, de Luis Vélez de Guevara.
El Nuevo Depositario y Nueva Depositaria de José Joaquín de Larriva contra Gaspar Rico, más literatura que periodismo CONCEPCIÓN REVERTE BERNAL 
Cf., por ej., Tomás Navarro Tomás, Métrica española. Reseña histórica y descriptiva, Madrid, Ediciones Guadarrama, 1972 ( $3^{\mathrm{a}}$ ed.).

25

Larriva no emplea etimológicamente los pronombres átonos, principalmente hace leísmo.
El Nuevo Depositario y Nueva Depositaria de José Joaquín de Larriva contra Gaspar Rico, más literatura que periodismo CONCEPCIÓN REVERTE BERNAL
Los textos que siguen en este Nuevo Depositario son una "Nota embetunada», una «Décima asnal» (con versos de cabo roto ${ }^{24}$ : «Ahora sí que vas Angu-/ a tu destino confor/ puesto que vas con alfor-», etc.), una «Adición Roncadora», otra "Adición Transeúnte», un «Tránsito Vindicativo» y una «Contra-Advertencia». Me detengo en esta última porque en ella nuevamente se manifiesta el ingenio de Larriva, sea o no muy original; doy un fragmento en el que habla el autor:

Después de haber trabajado el dialoguito de arriba, estábamos dudosos o indecisos si le $e^{25}$ imprimíamos o no le imprimíamos, porque eso de hacer hablar a los borricos no nos parecía a la verdad muy en el orden; cuando en esto, jzas!, cae en las nuestras manos un impreso en folio que comienza diciendo, con letrones muy gordos: EL TEATRO AL ILUSTRE PÚBLICO DE LIMA. Y, al punto, dijimos: imprimatur, pues si los teatros hablan, ¿por qué los borricos no han de hablar también? Los burros tienen tamaña lengua y tamaña boca con qué hablar y los teatros necesitarían hablar por la cazuela o por alguno de los palcos.

Larriva culmina el fragmento «parli-versando» (el neologismo es suyo) con una décima espinela dedicada a Rico y su burro. Este primer Nuevo Depositario concluye con una «Correspondencia oficial entre don Gaspar Rico y don José Bohorques, aquel cajonero que está frente a la cigarrería de don Mariano Tramarria, y que vendía Depositarios y asentaba Lotería», donde este último da la mala noticia a Rico de que sus Depositarios no se venden, ni siquiera para envolver, y que su lotería tampoco rinde ganancias.

El segundo Nuevo Depositario empieza con la continuación de la «suso-inserta cantilena» «Tran, larán, larán...» del español $y$, tras un trecho de camino y oír un gran estruendo:

Creyó al principio nuestro Rico que era el traquido estallante del carbónico sulfuroso que despedían o bostezaban o eructaban las bocas circulares hondas o íntimas [de] los cañones o pedreros del Ejército Real, a quien por ser día miércoles se juzgaba próximo o más próximo. Pero después conoció que eran guerrillas aéreas; es decir, que las nubes más o menos inmediatas, más o menos preñadas, se batían unas con otras y se tiroteaban entre sí, más abajo o más arriba de la atmósfera terrestre; es decir, en la región del fuego o ignifero sulfurante.
La burla del culteranismo, en sus metáforas barrocas y acumulación de esdrújulas, que se hace en este pasaje sobre los rayos que caen sobre Rico en su marcha, atraídos por el plomo de las letras de imprenta y las bolas de lotería, se cierra con un «SOLOLOQUIO SIMBÓLICO», fragmento de soneto de estilo gongorino:

Después que la comparsa refundente nos ha fundido desde el pie al cogote, después que en muladar puerco, indecente, nos ha enterrado el pícaro chingote; después que tanto y tanta malqueriente nos ha forzado a huir a todo trote, sufriendo soles, lluvias y serenos; también ¿̨trum, trum, relámpagos y truenos?

Como sigue diciendo Larriva en su «Contra-nota intermedia», «largo rato prosiguió nuestro Rico parli-versando y parli-prosando sobre su triste situación», hasta que topó con un lancero de las tropas españolas con el que entabla un «Diálogo hiperbólico». A la comicidad de la situación anterior se le añade otra nueva en este pequeño paso o juguete cómico entre Gaspar Rico y el soldado: D. Gaspar Rico pide al soldado su caballo, a cambio de ser nombrado Director particular de la Lotería Meridional sin plaza concreta; satisfecho con el trato, el soldado accede, pero requiere un nombramiento oficial, que improvisa rápidamente Rico dictándole un escrito, que copia el soldado a modo de eco, omitiendo el principio de las frases; por ej.: RICO: «Nos, don Gaspar Rico y Angulo...»/SOLD. «Angulo». Repentinamente, el soldado cree oír ruido de tropas y se marcha, dejando a Rico sin escrito y sin caballo. Al soldado realista, que se expresa con normalidad, se le escapa una expresión muy criolla: «Pues andando se hacen chancacas» (dulce de miel peruano de caña de azúcar) y en todo el paso Rico sigue hablando con un lenguaje pretencioso, enfático, con hipérbole, políptoton, repeticiones, plural mayestático, uso arcaizante de artículo más posesivo, palabras esdrújulas, etc. Doy fragmentos del discurso de Rico al soldado:

Oye y sabrás. Los Directores particulares son varios e muchos, y cada uno de ellos sólo dirige la lotería de un pueblo o lugar o provincia; cuando el Director general, que es solo o único, dirige las loterías de todos los pueblos o provincias de la América 
Meridional. Yo, yo, yo, y no otro ninguno, soy el tal Director general que también pudiera llamarse universal. [...]

Queremos que sepas que hemos quedado tan reconocidos a la fineza que nos hicisteis dándonos el tu caballo, que, aunque el estómago nos está llamando histérica o flatulentamente, nos hacemos sordos a sus voces o insinuaciones íntimas, y queremos que la primera diligencia sea despacharte el título de Director. [...]

Yo te habilito, ¡oh, Basilio Yeguas!, para que provisional o provisoriamente autorices o puedas autorizar todo lo que nos firmemos o rubriquemos.

Aquí Rico incluye una frase del célebre Ars Poetica de Horacio: "Omne tulit punctum qui miscuit utile dulci» (ha obtenido un consenso unánime quien unió lo útil con lo agradable) ${ }^{26}$; esta frase, de gusto ilustrado, la emplea Rico para explicar al soldado que, al ser simultáneamente Ministro honorario de la Hacienda Pública y Director general de la Lotería de la América Meridional, reúne ambos aspectos en su dedicación. Este Nuevo Depositario termina con otra décima con versos de cabo roto dedicada a Rico y con la «Epístola chimbadora del difunto Cojo Prieto dirigida a su albacea», enviada desde el Purgatorio, en la que el finado Prieto echa en cara a su testamentario, desde el más allá, haber visto «copiadas a la letra» sus frases en el Depositario de Angulo. Si como suele señalar la crítica, Larriva es Antonio Prieto Lazo de la Vega, «el Cojo Prieto», el limeño parece echar en cara al español el remedo de su estilo.

El tercer Nuevo Depositario se inicia con Larriva subido a una calesa conducida por un negrito, cuya lengua imita en el diálogo:

- Turru, ru, ru, ru, ru, ru, ru, ru, ru, ru, ru, ru, ru, ru, ru, ru, ru.

- Muchacho.

- Siñó.

- Tuerce por aquí.

- Iti calle no poré pasá.

- ¿Por qué?

- ¿No ve ese burrico mueta? Mula poré pantá.

- Tuerce, demonio, mas que te lleve la trampa a ti y a la calesa.

- Turru, ru, ru, ru, ru, ru, ru, ru, ru.

Desde allí dialoga con un amigo que encuentra en el camino, quien le reprocha el tiempo dedicado a los Nuevos Depositarios; Larriva se defiende:

-Yo escribo para mí solo; imprimo mis escritos porque me agrada verlos en letra de molde [...] ¿Yo gasto el tiempo de nadie? ¿No es mío el que gasto?

El amigo le replica recordándole su deber hacia la sociedad:

-Está Ud. muy equivocado en ese punto. Ningún hombre constituido en sociedad es árbitro absoluto de su tiempo $[\ldots]$

La siguiente detención de la calesa, bajo el título de «Diálogo atrasadillo», está relacionada con la lotería:

- Cuarenta y cinco miiiiiiil, ochocieeeeeentos, noventa y sieeeeeeete.

- Para, muchacho. Dígame Ud., mi amigo, ¿qué significan estos gritos musicales o armónicos?...

- La rifa o el sorteo de los números o billetes de la lotería nacional.

El voceo de los números continúa con sus onomatopeyas y en el transcurso del diálogo Larriva explica razonadamente el engaño que supone para el vulgo la lotería. En la siguiente décima dedicada a Rico la denomina la «ladronera nacional». El «Variando», a continuación, aplica a la lotería el refrán «Lo que es del agua, el agua se lo lleva», pues, «Lo que es de la trampa, se lo lleva la trampa».

Tras una «Octava» y una «No cuarteta» (en realidad, quintilla) con versos de cabo roto, otra vez para Rico, en el «Variando sin variar» Larriva retoma la historia del español en su viaje: Asustado, al oír el ruido que ocasionan cuatro desertores del ejército español que cabalgan, Rico se oculta en un pesebre y los borricos que hay ahí, viendo su levita verde, la creen comida, dejándolo de esta forma:

Entraron los soldados y no podían contener la risa, al ver a nuestro Rico en mangas de camisa, con su gorro negro y con su barba de dos dedos, forcejeando con los burros que se lo querían comer. Pero, en fin, a sablazos, los separaron del pesebre.

Angulo explica a los soldados lo sucedido, primero en prosa y luego en la siguiente «No octava» (una décima asonante con versos de cabo roto):

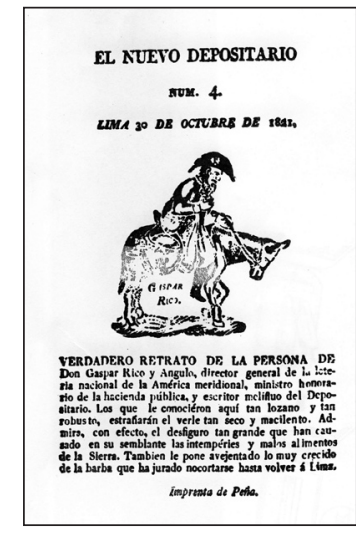

Inicio de El Nuevo Depositario 4 tomado de la ed. facsímil, Lima Separata de: Boletín de la Biblioteca Nacional, 57-58 (1971).

26

Literalmente: se llevó todos los votos el que combinó lo útil con lo agradable; cf. Quinto Horacio Flaco, Epístolas. Arte Poética Fernando Navarro Antolín (edición crítica, traducción y notas), Madrid, CSIC, 2002 
Como se recordará, el color verde de su chaqueta hace que los compañeros de la escuela pongan el mote al protagonista; cfr. cap. II, por ej., en El Periquillo Sarniento, Edición de Carmen Ruiz Barrionuevo, Madrid, Cátedra, 1997.

28

Cf. Don Quijote de la Mancha, Edición del IV Centenario, Madrid, RAE, 2004, Parte II, cap. $X V I I$, en el que don Quijote pide que abran la jaula donde llevan dos leones, que ignoran al caballero; lo cual permite que salga indemne del lance $y$ tome el apodo.

29

Zanutelli, Periodistas Peruanos...., op. cit., p. 11, subraya la novedad que supone el uso de esta ilustración para el periodismo peruano decimonónico.

30

Debe de tratarse del General D. Ignacio de Escandón, que cita Marcelino Menéndez Pelayo en su Historia de la poesía Hispano-Americana, quien en 1762 celebró con un romance, con «el estrafalario rótulo de Época Galicana egira Gali-lea» la apertura de la primera casa pública en Lima destinada a las peleas de gallos; cf. Edición preparada por Enrique Sánchez Reyes, Santander, Aldus, S.A de Artes Gráficas, MCMXLVIII, t. II, p. 147.

31

Su casi coetáneo Esteban Terralla y Landa, autor de Lima por dentro y fuera (1797).

El Nuevo Depositario y Nueva Depositaria de José Joaquín de Larriva contra Gaspar Rico, más literatura que periodismo CONCEPCIÓN REVERTE BERNAL
Como era verde-esmeral -

la nuestra leva o levi-,

creyeron estos borri-

que éramos tercio de alfal-.

Cual nos desguaza una fal-,

cual nos rompe los boto-,

y, después de que en pelo-

nos dejaron, insolen-,

quisieron con los sus dien-

morder la nuestra perso-.

El color de la levita de Angulo, al que se aludió también anteriormente, hace pensar en la «chupita» o chaquetita verde de Periquillo en El Periquillo Sarniento, del mexicano José Joaquín Fernández de Lizardi (1776-1827), coetáneo de Larriva y Rico y también célebre en el periodismo ${ }^{27}$. $\mathrm{Me}$ parece interesante esta posible referencia literaria porque indicaría unas relaciones culturales entre las capitales de los dos Virreinatos principales. En la bibliografía sobre este antiguo periodismo peruano se menciona la existencia de un diario titulado El Pensador Peruano, cuyo nombre evoca la publicación ligada al seudónimo de Fernández de Lizardi: El Pensador Mexicano, de los mismos años, aunque fuesen de diferente orientación.

Los soldados que contemplan la escena no pueden evitar reírse de la desgracia de Rico y de sus explicaciones, y aquí se introduce la voz del propio Larriva con la siguiente «Octava», donde hace patente la vinculación con Cervantes:

Don Quijote, el manchego, ¡vaya, vaya!, llamóse el Caballero de los Leones, porque intentó con dos una batalla que se quedó tan solo en intenciones. Y tú que entraste, con burral canalla, en efectiva lid de mordiscones, ¿derecho no tendrás, aunque hecho añicos, El Caballero, a ser, de los Borricos?28.

Los soldados llevan consigo a Rico «para divertirse en el camino»-como hacían con don Quijote- y se describe su figura:

Luego que estuvo montado en un burro que ellos le proporcionaron, en mangas de camisa, con sombrero de picos y con la barba muy larga -porque es de advertir que, a su salida de Lima, prometió no afeitarse hasta la vuelta- [...]
Larriva concluye este periódico con un «Variandito», donde dice que Gaspar Rico perdió la A y la B de su imprenta en el camino, lo que no se refleja, no obstante, en la escritura de los restantes Nuevos Depositarios.

El Nuevo Depositario, número 4, se abre con un dibujo de don Gaspar Rico sobre un burro $^{29}$, con sombrero de picos, barba larga, levita puesta -no en mangas de camisa como se acaba de describir-, llevando sus alforjas; al pie del mismo se dice:

VERDADERO RETRATO DE LA PERSONA DE Don Gaspar Rico y Angulo, Director general de la lotería nacional de la América Meridional, ministro honorario de la hacienda pública y escritor melifluo del Depositario. Los que le conocieron aquí tan lozano y tan robusto, extrañarán el verle tan seco y macilento. Admira, con efecto, el desfiguro tan grande que han causado en su semblante las intemperies y malos alimentos de la Sierra. También le pone avejentado lo muy crecido de la barba, que ha jurado no cortarse hasta volver a Lima.

Larriva introduce ahora una silva a «Rico inmortal», especie de himno heroico-burlesco en el que se congratula de que exista el arte del retrato para inmortalizar a los grandes hombres, como sucede ahora con Rico y sucedió en la Antigüedad Clásica con Tibulo, Cicerón, Horacio, Catulo, Virgilio, Diodoro, Homero y Julio César; para saber, como en el caso de este último:

...si fue manco o si fue cojo, orejón o bisojo, si tuvo color blanco o de mulato, y si fue narigón o si fue ñato?

En el curso del himno, con anáfora y exclamaciones, Larriva dice que Rico encontrará en el templo de la fama, junto a sus Depositarios, los poemas «del Comandante Escandón» ${ }^{30}$, de «tu digno rival, el Cojo Prieto", de Terralla ${ }^{31}$, aunque «Toditos, casi, son de infantería». En el mismo lugar, Rico hallará el jumento de Sancho Panza, el único que se admite con el suyo, ya que como explica, con anfibología, «pues que tan sólo, por personas tales,/ allí se admiten estos animales». El himno queda rematado en unos versos que podía haber escrito Juan del Valle Caviedes:

¡Oh, felice Gaspar!, cosa de zumba viene a ser para ti la horrible tumba; 
tú te puedes reír del garrotillo, del dolor de costado y tabardillo, y también de la angina, mas que nunca en el mundo hubiera quina.

Que se mueran los bobos

cuyas almas escasas, contentas con vivir en el reposo, nada hicieron extraño ni ruidoso; mas tú, que con tu imprenta y con tus globos unas cosas hiciste tamañazas ${ }^{32}$, imposible es Angulo que te mueras, aunque tú mismo, tú, morirte quieras.

Aunque todos los males

que a los tristes mortales en cadáveres tornan o en difuntos hoy se conspiren juntos, aun inclusive el bicho y la disentería para acabar contigo; tú, con el burro, tu mejor amigo, tu imprenta, lotería y tus escritos bellos, te burlarás de ellos, y orondo y hueco llegarás al nicho, dó, a pesar de malsines y vestiglos, vivirás por los siglos de los siglos.

Después de la muy breve «Sobrenota embetunada» que viene a continuación, en las siguientes «Variando sin variar la variación», «Noticia contraria o no conforme a la anterior» y "Contra-nota perpendicular», Larriva nos informa de que el Virrey La Serna ha nombrado a don Gaspar Rico «(no de plata)», Intendente de Huancavelica. Larriva confiesa: "Siempre que hablamos u oímos hablar de la tal Intendencia, se nos viene a la memoria sin poderlo remediar, la Ínsula de Sancho» ${ }^{33}$. Esto le «da gana de gritar» un romance dividido en estrofas de vivas, que varían solamente en su segundo verso; la primera es:

Viva el nuevo Sancho,

y obras mil imprima;

viva el Intendente

de Huancavelica.

Los segundos versos de todas las estrofas son los siguientes, que acaban apuntando otra vez a la identificación devaluadora entre don Gaspar y su jumento: "y obras mil imprima»/ "para que haga rifas»/ "que nació en Castilla»/ «viva su levita»/ «mil leguas de Lima»/ «su borrico viva».
El Nuevo Depositario número 5 supone un paréntesis en el relato de las andanzas de don Gaspar en la sierra peruana. Estando Larriva en una casa «adonde concurren diariamente varias personas de humor», llega un mocito con una noticia que levanta expectación, creyéndose que es «alguna glosa del Ciego de la Merced» o «algún soneto del célebre Caviedes» ${ }^{34}$, pero que resulta ser una nota del mismo Rico, donde firma con sus once apellidos: «Rico de Angulo, Tricio y Querejazu, Reynares, Ruiz de Lovera, Aragón, Gonzales, Torres y Villasana». Ello suscita las chanzas de los presentes, a excepción de un Reverendo que había sido «de uña y carne con Rico» en Lima, y quien interviene en la conversación para glosar la ilustre genealogía de don Gaspar de forma disparatada. Entre la prosa y versos de este número Larriva hace algunas bromas de doble sentido sexual; sirva de muestra la siguiente décima:

Si en los siglos delanteros

has de vivir por tu ciencia,

por la tu noble ascendencia

ya has vivido en los traseros.

Rompe ya los tus tinteros

y tu pluma de alcatraz ${ }^{35}$;

pues, aunque no escribas más

$\mathrm{y}$ te metas en un cuerno,

serás, Villasana, eterno,

por delante y por detrás.

En el debate literario de unos y otros, deseo destacar intervenciones que se refieren a la versificación. Por ejemplo, al interrumpir Larriva el discurso del Reverendo para corregir Angulo por Angul, el Reverendo le contesta:

Pero me coge muy de nuevo el que un hombre que sabe hacer octavas se ande parando en una letra, y principalmente en una $\mathrm{O}$, que en su propia figura está diciendo que es lo mismo que un cero.

El grupo decide escribir cada uno un acróstico por apellido de Angulo, los que no se reproducen en el periódico. Este Nuevo Depositario da fin con el siguiente diálogo entre Larriva y su ayudante:

\section{VARIANDO}

¡Zapata! -Señor- ¿Cómo estamos? -Faltan siete renglones para llenar el pliego. -¿Siete? Pues vaya una
32

Con seseo, lo indico aquí porque afecta a la rima: escasas-tamañasas.

33

Don Quijote de la Mancha, Parte II, caps. XLV-LIII.

34

Larriva completa esta nómina de poetas satíricos limeños con $\mathrm{Fr}$. Francisco del Castillo, "el Ciego de la Merced» (Lima, 17161770) y Juan del Valle y Caviedes (Porcuna, Jaén, 1645-Lima, 1698). Un buen resumen en Eva Valero Juan, Lima en la tradición literaria del Perú. De la leyenda urbana a la disolución del mito, Lleida, Edicions de la Universitat de Lleida, 2003.

35

Con seseo.
El Nuevo Depositario y Nueva Depositaria de José Joaquín de Larriva contra Gaspar Rico, más literatura que periodismo CONCEPCIÓN REVERTE BERNAL 


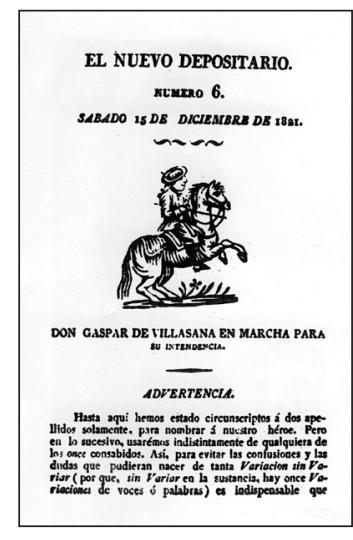

Inicio de El Nuevo Depositario 6 tomado de la ed. facsímil, Lima, Separata de: Boletín de la Biblioteca Nacional, 57-58 (1971).

36

Baltasar Jaime Martínez Compañón y Bujanda (Navarra, 1737 Bogotá, 1797) mandó pintar centenares de acuarelas del recorrido que hizo por su diócesis peruana en la segunda mitad del siglo XVIII, las cuales constituyen un valioso testimonio.

37

Dejo la palabra con la terminación del francés sauvage, que permite la rima con Lesage, escrito en el impreso antiguo «Le-Sage».
El Nuevo Depositario y Nueva Depositaria de José Joaquín de Larriva contra Gaspar Rico, más literatura que periodismo

CONCEPCIÓN REVERTE BERNAL
SEGUIDILLA ABOLERADA

Once las letras son

del aguardiente,

y once los apellidos

del Intendente.

¡Once felice!

Más que el doce y el trece, catorce y quince.

El Nuevo Depositario número 6 vuelve a encabezarse con un dibujo de don Gaspar, pero donde se le ve ahora rejuvenecido y contento, con la barba rasurada y a lomos de un caba1lo. La figura es semejante a pinturas peruanas del XVIII, como las encargadas por el Obispo de Trujillo D. Baltasar Jaime Martínez Compañón ${ }^{36}$. A pie de dibujo se dice escuetamente: «DON GASPAR DE VILLASANA EN MARCHA PARA SU INTENDENCIA» (ILUSTRACIÓN $\mathrm{N}^{\circ} 3$ ). El primer texto del periódico es una «Advertencia» donde Larriva señala que a partir de ahora se referirá a Rico por sus once apellidos. Le siguen:

\section{SOBREADVERTENCIA}

Hasta aquí nuestro D. Gaspar sólo ha sido Caballero de los borricos, pero desde hoy será también conocido por el nombre de Caballero de los once apellidos:

Imitando al manchego Don Quijo-

que, según Benengeli, fue el prime-,

de la Triste figura Caballe-

y después Caballero de los Leo-.

\section{CONTRADVERTENCIA}

¡Con qué rasgos tan bellos y graciosos

en los tiempos antiguos se escribieron

las vidas de los héroes fabulosos

que dizque se dijeron

Don Quijote y Gil Blas de Santillana!

Y ¿teniendo yo un Tricio o Villasana,

héroe real y efectivo,

y tanto, que los dos, más afamado,

cuanto va de lo vivo a lo pintado;

por qué causa no escribo

con más sal que Cervantes y Lesage?

¡Vaya, vaya, que soy un gran salvage! ${ }^{37}$

La mención de la novela picaresca francesa de Alain-René Lesage (1668-1747) vuelve a enlazar los Siglos de Oro con el XVIII y con Fernández de Lizardi. La historia de don Gaspar Rico se reanuda con su entrada triunfal a Huancavelica, en medio de fuegos artificiales descritos onomatopéyicamente:
Chiiitum, chitum, chitum, chiiiiiitum, tum, tum, tum, chiiliiiiiiiiiitum, tum, tum, tum, tum, tum, tumtumtum, chiii, chiii, chiiii, tum, tum, tum, tumtumtum, tum, tum, tum, tum, chitum, chitum, chiiliiiiiiii, tum, tum, tum, tum, tum, tumtum.

Sin embargo, como le pasaba al desventurado don Quijote, la mala fortuna hace que estalle un cohete entre las patas de su caballo y Rico vaya a parar sobre un montón de basura, que amortigua el golpe, pero que no impide que se golpee la cabeza y permanezca inconsciente hasta el día siguiente, cuando van a presentarse ante él, en el lecho de convalecencia, las autoridades de Huancavelica. Su curación le ocasiona «una jeringa y dos ventosas sajadas que le hizo aplicar en el tiro el protomédico de allí». En el diálogo entre las autoridades y el personaje loco-cuerdo que es Rico, el español contesta a los cumplimientos que recibe de la siguiente manera:

Por muy sensible que haya sido a este ayuntamiento el nuestro porrazo de anoche, más sensible nos fue a Nos; porque cosa vieja es que nadie siente el mal como aquél que le padece.

Tras comunicar a Rico que todo está dispuesto para la solemne misa de acción de gracias por su llegada, él les contesta:

...pegaba, mucho mejor, una misa de salud, que no de acción de gracias. Porque esto de dar gracias por haberse pegado un porrazo en las costillas no nos parece nada natural; a menos que entendamos, rigurosa o más rigurosamente, aquello de gracias a Dios por todo.

De ahí pasamos a leer el sermón que imparte en la susodicha misa «un tapado a quien llaman allí Pico de oro», digno sucesor del famoso predicador Fray Gerundio de Campazas, de la obra homónima del Padre Isla. El sermón aplica metafóricamente a don Gaspar los tres regalos: oro, incienso y mirra, que ofrecieron los Reyes Magos a Jesús, aprovechando la coincidencia del nombre del español con uno de ellos; el extravagante discurso alterna expresiones cultas y vulgares. A modo de muestra y por volver a recordar al protagonista de la famosa novela de Lizardi, con una graciosa aliteración de periquito hablador, reproduzco la última parte del sermón de recibimiento: 
...Yo encuentro, sin embargo, una pequeña diferencia ventajosa a Su Señoría. La diré: el otro Gaspar era Rico de oro solamente, Aurum, pero Su Señoría es Rico de talentos, Rico de luces, Rico de ingenio, Rico de arbitrios, Rico de proyectos, y es, en fin, Rico de tantas y tantas cosas, que si, conforme le pusieron en la pila el nombre de Gaspar, le ponen el de Pedro, por fortuna, pudiera decirse a sí mismo, como aquellos verdosos pajarillos que se crían en las montañas vecinas a Guayaquil, Periquititito Rico, Rico, Rico, de Puerto-Rico. ¡Oh, Huancavelica! ¡Qué ventura la tuya! ¡Cuánto te envidiarán todas las provincias de la Sierra! Ahora sí que mereces el nombre de Villa-Rica; más bien que el año de quinientos setenta y dos, en que te le dio tu fundador Francisco de Toledo. Y Su Señoría, también merece ya, mejor que antes, el primero y más precioso de sus once apellidos; quiero decir, que aunque Su Señoría fue Rico desde que su madre le parió, nunca fue tan Rico como ahora. Ya habéis visto, oyentes míos, el plan de mi discurso. En la primera parte os haré ver que Villa-Rica es más Rica desde que es mandada por Rico. Y en la segunda, que Rico es más Rico, desde que manda a Villa-Rica. AVE MARÍA.

Maliciosamente, interrumpe aquí Larriva diciendo: «No copiamos el sermón entero, por no fastidiar a los lectores». Cuando sale de la iglesia Rico, ve cómo le cae del cielo una lluvia de papeletas ensalzándolo en seis redondillas, cada una de las cuales finaliza en uno de sus apellidos. Otra vez, metaperiodísticamente, Larriva concluye este número de El Nuevo Depositario:

\footnotetext{
DIÁLOGO

- ¡Zapata!

- Señor.

- ¿Hoy también faltan siete renglones para llenar el pliego?

- Hoy faltan ocho.

- Bien. Pon, pues, esta octava que mandó Villasana a una joven de Huancayo, al partir para Huancavelica.
}

\section{OCTAVA}

Listo tenemos ya nuestro caballo para partir, ¡oh, Rosa! ¡Oh, cruel destino! Partimos, mas dejamos en Huancayo ${ }^{38}$ el nuestro corazón fino o más fino; no sea que fiero, tremebundo rayo, penetre el nuestro cuerpo en el camino y queme la tu imagen, joh, tirana!, homicida de Tricio y Villasana.
Si los números anteriores de El Nuevo Depositario están fechados entre el 18 de agosto de 1821 y el 15 de diciembre del mismo año, con el único número de la Nueva Depositaria Larriva da un salto hasta el 1 de mayo de 1825, y dice en el encabezamiento: «Escrita con el objeto de mandársela a don Gaspar Rico, residente en el castillo del Callao, por un correo extraordinarísimo, aéreo-metálico-sulfúricotronante». Esta «residencia» de Rico, dicha con ácida ironía, es su último refugio en aquel lugar, con las tropas españolas comandadas por Rodili39.

El primer texto de este periódico se titula «Entrada de pavana», expresión que define el Diccionario de la Real Academia Española como «cosa fútil o impertinente, dicha o propuesta con misterio o ridícula gravedad». Escrita en silva, describe el envío del periódico de Larriva acompañando las bombas que caen sobre el Callao, con un trayecto cósmico, como un baile grave, de movimientos pausados (la pavana), con el deseo que llegue a la persona de Rico:

¡Quién como tú, Depositaria mía, feliz Depositaria!, que, conducida por ligera bomba, que va con su espoleta, hendiendo el aire en luminosa comba, cual un tiempo le hendía

el pequeño farol o luminaria que llevaba en el rabo mi cometa, con más celeridad que la del viento, vas a trepar al alto firmamento y, después de correr regiones bellas, pobladas de planetas y de estrellas, ver de cerca a Saturno con su calva y al Lucero del alba, a Febo conocer que da los días, y a las Cabrillas siete y tres Marías, y pasar junto a Virgo y el Cangrejo, y el dios terrible de la cruda guerra, descender otra vez sobre una tierra do la gloria tendrás inapreciable de saludar al CASTELLANO VIEJO [sic]; a aquel varón ensine, incomparable, sin par entre la gente que habita del un polo al otro polo; a aquél héroe famoso y prepotente que, del Callao, en pie mantiene, solo, los altos torreones, que, a no ser su pluma tan de fuego, hubieran sucumbido, desde luego, a pesar de sus muros y cañones.
38 Rima con yeísmo.

39

La valiente resistencia del Brigadier don José Ramón Rodil (1789-1853) en el sitio del Callao, tras el cual sobrevivió volviendo a España, fue considerada un acto quijotesco por algunos, tal como refleja una estampa satírica de 1825 . Véase José Ramón Rodil, Memoria del sitio del Callao, Vicente Rodríguez Casado y Guillermo Lohmann Villena (edición y nota preliminar), Sevilla, Escuela de Estudios Hispano-Americanos, 1955. En las pp. 261-262 se recoge un escrito de Rodil fechado el 24 de abril de 1825, dirigido a don Manuel Blanco Encalada, Almirante de la Escuadra de Chile, en el que le dice: "Como sigue el buen humor del Señor Rico, también yo continúo remitiendo a $\mathrm{V}$. el número de Depositarios que ha dado a luz desde el 3 del corriente».

\footnotetext{
El Nuevo Depositario y Nueva Depositaria de José Joaquín de Larriva contra Gaspar Rico, más literatura que periodismo CONCEPCIÓN REVERTE BERNAL
} 
40

Sic, poeta.

41

Parte I, cap. XXI.
El Nuevo Depositario y Nueva Depositaria de José Joaquín de Larriva contra Gaspar Rico, más literatura que periodismo

CONCEPCIÓN REVERTE BERNAL
[...] Me congratulo

de poder dirigirte este mensaje.

$\mathrm{Y}$, al cielo plegue que el volante paje

que le va a conducir con tanta bulla,

tan junto caiga a la persona tuya

que a entregártele llegue en propia mano,

envuelto cual cartucho o cual barquillo,

a ti, que eres dos veces castellano,

y honor de la Castilla y del Castillo.

La ligereza de esta silva enmascara la realidad, sólo entrevista en el verso que habla del «dios terrible de la cruda guerra», y contrasta con el lenguaje del «Diálogo intercalante» que Larriva sitúa a continuación, donde intervienen don Gaspar Rico y el impresor José Masías. Rico lleva a Masías el número 160 de su Depositario, que acaba de concluir, donde, según dice:

RICO [...] anunciamos, con el idioma de la claridad divertida, verdades que aprovechan mucho a muchos, y que intaravintanticulan... tanto... a tantos. [... Empieza a leer el «Invitatorio antifonado» del Depositario:] Molestados toda la noche, próxima o más próxima, por un cierto calorcillo insinuante o intenso que nos hizo arrojar por los minutísimos poros de la nuestra epidermis o cutícula hasta el humor linfático convertido en sudorífico, y por una comparsa de zancudos más o menos cantores, más o menos punzantes, que se empeñaron en llenar la nuestra cara de esos tumorcillos pruriginosos, que piden pronto o más pronto el auxilio de las uñas, y en amolar los tímpanos delicados de las nuestras orejas con el infernal diapasón de su música ingrata o descompasada, no nos ha sido posible o fácil saludar siquiera el poltrón de Morfeo.

El parlamento de Rico, que continúa con su enrevesado estilo, alterna lo cómico y lo serio; así, Larriva imagina que Rico, en su desvelo, piensa:

Después de catorce minutos y medio de una meditación más profunda o menos superficial, en que consultamos al consejo de la nuestra sesera peculiar o privativa sobre futuros contingentes o no contingentes, condicionales o no condicionales, relativos o no relativos, a la suerte próspera o adversa de quince millones de individuos personalizados o de personas individualizadas, iguales en idioma, en religión y en costumbres, pero más o menos desiguales en sexo, en inclinaciones, en opiniones, en designios, en vicios y virtudes, me rasqué la cabecilla por lo peliagudo del negocio. Y, resuelto a trasladar al papel o proporción de mi incapacidad relativa, mis ideas zumbáticas salpicadas con un trocito de risa sardónica, para darlas al público de un mundo o de dos mundos con todas sus inducciones, conexiones, aducciones y deducciones, me calé el gorro y los botines y así, en mangas de camisa, como suelen estar los mozos de pulpería para vender los plátanos y el queso, puse los huesos de pueta $^{40} \mathrm{y}$ me arrimé al bufete.

Ello no quita para que Rico responda al «traquido-estallante-carbónico-sulfuroso» de las bombas:

histérica o flatulentamente con otro sonido semejante o idéntico, expeliendo con más o menos fuerza, por el intestino recto, la fracción atmosférica apretada o comprimida en su mayor o menor elasticidad, entre las sinuosidades intercalantes de las tripas de nuestro mondongo.

El diálogo entre Rico y el impresor sigue centrado en los rebuscados títulos que pone don Gaspar a los artículos de su Depositario, como sucede en «Nota parabólica», que es el título que Rico justifica a continuación. Al arreciar el ruido de las bombas, el impresor, asustado, se mete bajo una mesa y entonces Rico decide colocarse un perol en la cabeza para resguardarse, sin importarle que esté lleno de tinta; es claro que Rico aquí evoca a don Quijote con su bacía de barbero ${ }^{41}$. Para Rico, lo que defiende el castillo del Callao no es la espada de Rodil, sino los escritos de su pluma. El diálogo entre Rico y el impresor queda interrumpido por un temblor de tierra, que los hace salir corriendo a una plaza.

Larriva intercala ahora un «Gran descubrimiento»: Rico ha logrado unir con su cabeza dos grandes continentes. En prueba de ello, reproduce Larriva la supuesta nota dirigida por Rico al Virrey, en 1822, en el Cuzco, en la que el riojano solicitaría un pasaporte para volver a Europa; en la misma nota, Rico se queja de «la necia debilidad de haber defendido la causa española en estas regiones». Esta Nueva Depositaria lleva como colofón un poema escatológico dedicado a Rico: «Variandito». Se trata de una octava al estilo de Quevedo o Valle Caviedes, donde Larriva se dirige a una bomba, personificándola, y le pide: «busca por su detrás a Villasana/ y clávatele en forma de almorrana». Aunque Rico no murió por efecto de las bombas que cayeron sobre el Callao, sí lo hizo en aquel lugar, por enfermedad, en 1825. 
En la edición de textos de Larriva hecha por el Coronel Odriozola éste añade, tras la transcripción de los periódicos que he comentado, una Octava autoelogiosa de un vate y dos crueles poemas de Larriva a la muerte de Rico. Doy los dos últimos:

EPITAFIO que se puso en el Castillo del Callao, sobre la losa que cubre el sepulcro de D. Gaspar Rico.

Detén esa tu planta presurosa, caminante, y sacando tu denario, híncate de rodillas en la losa y reza devotísimo un rosario; pues el alma de cántaro aquí posa del que el mundo llamó Depositario. Toda su vida la pasó de pillo; en Castilla nació, murió en Castillo.

\section{OTRO}

Aquí un tremendo enjambre de gusahinca feroce su agusado dien-, en el cuerpo de aquél que el suyo infaen las almas hincó de tantas gen-.

Aquí yace podrido Villasa-, saltad, oh, pasajeros, de conten-; ya, de la activa, se volvió en pasi-. ¿Le vistéis mordedor? Vedle mordi-.

Si la metáfora del acto de morder para la sátira es corriente, recordemos que en Perú se publica durante el siglo XVIII el Diente del Parnaso, de Juan del Valle y Caviedes.

Larriva, mediante estos textos, manifiesta su aversión hacia Rico, convirtiéndolo en un personaje caricaturesco. Sin embargo, en algunos libros recientes de historia no es visto así, sino como un respetado comerciante limeño de ideología liberal, que no deseaba la Independencia del Perú, sino una serie de reformas que lo modernizaran y que, temeroso de revanchas o consecuente con sus ideas, acompañó al Virrey La Serna en su dura marcha al interior del territorio, llegando hasta la defensa del Callao por Rodil ${ }^{42}$. Como señalé al principio, más adelante el propio Larriva arremeterá contra las tropas extranjeras que apoyaron la Independencia de su país. Contradicciones todas estas, características de un tiempo convulso, de legítimas aspiraciones, plasmadas en acciones difíciles y en textos literarios que no pueden ser interpretados como un fiel reflejo de la realidad, aunque puedan transmitir mejor que otro tipo de escritos las mentalidades del período histórico.

Para acabar, otro aspecto en el que deseo insistir es en la modernidad literaria de Larriva, que parte de su conocimiento de la tradición de los Siglos de Oro y de las novedades del Neoclasicismo. Leyendo sus textos me han venido a la mente las palabras de Rubén Darío en el «Prefacio» de Cantos de vida y esperanza:

En cuanto al verso libre moderno... ¿̨no es verdaderamente singular que en esta tierra de Quevedos y de Góngoras los únicos innovadores del instrumento lírico, los únicos libertadores del ritmo, hayan sido los poetas del Madrid Cómico y los libretistas del género chico? ${ }^{43}$
42

Véase, por ej., Martínez Riaza, op. cit. y Patricia H. Marks, Deconstructing legitimacy. Viceroys, Merchants, and the Military in Late Colonial Perú, University Park. Pennsylvania, The Pennsylvania State University Press, 2007.

43

Cito por Azul... Cantos de vida y esperanza, José María Martínez (ed.), Madrid, Cátedra, 1995 pp. 333-334 